\title{
High frequency of karyotype variation revealed by sequential FISH and GISH in plateau perennial grass forage Elymus nutans
}

\author{
Quan-Wen Dou*1), Zhi-Guo Chen"), Yong-An Liu' ${ }^{1)}$ and Hisashi Tsujimoto' \\ 1) Key Laboratory of Adaptation and Evolution of Plateau Biota, Northwest Plateau Institute of Biology, the Chinese Academy of \\ Sciences, Xining, 810008, China \\ 2) Faculty of Agriculture, Tottori University, 4-101 Minami, Koyama, Tottori 680-8550, Japan
}

\begin{abstract}
Elymus nutans L. (StHY, $2 n=6 x=42$ ) is extensively selected from the natural population and domesticated as perennial grass forage in the Qinghai-Tibet plateau in China due to its high tolerance to environmental stresses, such as cold and drought. Karyotyping was conducted in 12 randomly selected plants by sequential fluorescence in situ hybridization (FISH) and genomic in situ hybridization (GISH). GISH discriminated St, $\mathrm{H}$ and $\mathrm{Y}$ genomes, indicating that $E$. nutans has retained its ancestral genome, and large chromosomal rearrangements have not occurred. However, FISH using an AGG satellite and $A f a$-family repetitive sequences, revealed marked variation in the signalling patterns of most of the chromosomes. Many of the plants carried chromosomes with a specific pattern in the homozygous state, indicating that self-pollination or sib-crossing occurs in small populations during selection for domestication. In addition, several intergenomic translocations appeared, possibly caused by homoeologous chromosome recombination. The nature of the polymorphisms seen in the chromosomes of the domesticated population of E. nutans is discussed.
\end{abstract}

Key Words: perennial grass forage, Elymus nutans, karyotype variation, FISH, GISH.

\section{Introduction}

The genus Elymus L., which includes as many as 150 species, is the largest and most widely distributed genus in the Triticeae tribe of family Poaceae (Löve 1984). Elymus nutans $\mathrm{L}$. is a commonly distributed Elymus species in China and grows on grassland, bush land, river banks, mountain slopes, and swales, at altitudes from $1000 \mathrm{~m}$ up to $5000 \mathrm{~m}$ ( $\mathrm{Lu} \mathrm{1993)}$ and is tolerant to various environmental stresses associated with high altitude, such as cold and drought. In the Qinghai-Tibet plateau, vigorous plants are selected from the natural population and used as perennial forage crops. A cytological study has suggested that $E$. nutans is hexaploid $(2 n=6 x=42)$, and has three genomes: St, Y and H (Lu 1993). The St genome originates from the genus Pseudoroegneria and the $\mathrm{H}$ genome from Hordeum, but the origin of the $\mathrm{Y}$ genome is unknown (Wang et al. 1995). Recent molecular phylogenetic studies have suggested that the St and Y genomes may have originated from the same ancestors (Liu et $a l$. 2006). In this species, chromosomal rearrangements and karyotype variations are shown by assessing intraspecific hybrids and mitotic chromosomes (Lu 1993, Zhang et al. 2008). Knowledge of karyotype variation is helpful in selecting stable plants for breeding forage crops. However, the cytological analysis of this species is very limited.

Communicated by Donghe $\mathrm{Xu}$

Received September 8, 2009. Accepted October 30, 2009.

*Corresponding author (e-mail: douqw@nwipb.ac.cn)
Molecular cytogenetic analysis using genomic in situ hybridization (GISH) and fluorescence in situ hybridization (FISH) has provided powerful methods to detect karyotype variation. GISH using the total genomic DNA of an analyzer (a species with a known genome) as a probe revealed intergenomic translocations, as well as the presence, or absence, of the analyzer genome in polyploid species (Ørgaard and Heslop-Harrison 1994). FISH with chromosome-specific repetitive sequences or microsatellites as AAG identifies each chromosome in the genomes (Tsujimoto et al. 1997, Cuadrado and Schwarzacher 1998, Pedersen et al. 1996). We here adopted FISH/GISH analyses to the chromosomes of $E$. nutans to reveal intraspecific chromosomal variation.

\section{Materials and Methods}

\section{Plant materials}

Seeds of domesticated E. nutans were kindly donated by the Qinghai Grassland Management Station, China. The original materials were collected from the natural populations in regions around Qinghai Lake (altitude 3000-3500 $\mathrm{m}$ ) in Qinghai about 10 years ago by the breeders. They were then selected and domesticated as forage crops.

Seeds of Elymus sibiricus L. (StStHH) were collected in Xining, Qinghai. Hordeum chilense (HH) and Pseudoroegneria stipifolia (StSt) are maintained in the Laboratory of Plant Genetics and Breeding Science, Tottori University, Japan. 


\section{In situ hybridization}

An $A f a$-family repetitive sequence was amplified by PCR, as described previously by Nagaki et al. (1995), with a template DNA of E. sibiricus genomic DNA. The sequence was separated using agarose-gel electrophoresis. Genomic DNAs of $H$. chilense and $P$. stipifolia for the probes of GISH were fragmented by autoclaving at $120^{\circ} \mathrm{C}$ for $2 \mathrm{~min}$ before labelling. DNA was labelled with fluorescein-12-dUTP or tetramethy1-rhodamine-5-dUTP using the random primer method (Gene Images ${ }^{\mathrm{TM}}$ Random Prime Labelling Module, Amersham Bioscience). The synthesized microsatellite sequence $(\mathrm{AAG})_{10}$ was labelled with tetramethy1-rhodamine5-dUTP using the 3'-end method (Gene Images ${ }^{\mathrm{TM}} 3^{\prime}$ Oligolabelling Module, Amersham Bioscience).

The FISH and GISH procedures were followed as described previously by Kishii et al. (1999), with minor modifications. For the first hybridization, DNA denaturation was carried out in $0.2 \mathrm{M} \mathrm{NaOH}$ in $70 \%$ ethanol at room temperature for $10 \mathrm{~min}$. The sequential hybridization procedure was as follows: after photography of the first probing, cover slips were removed and the slides were washed in $2 \times \mathrm{SSC}$ for 20 min at room temperature and briefly dried; the mixture of the second hybridization was applied to the slide without denaturation. The following steps were the same as for the first hybridization. Several hybridizations can be conducted on the same chromosome preparation by repeating the steps above. GISH probing with labelled genomic DNAs of $H$. chilense $(\mathrm{HH})$ and $P$. stipifolia $(\mathrm{StSt})$ was carried out separately to avoid interference between the probes. Chromosome preparation was first detected by the $H$. chilense probe that was labelled with fluorescein-12-dUTP. After post-hybridization washing, the chromosome preparation was second detected by the $P$. stipifolia probe labelled with tetramethy1-rhodamine-5-dUTP. No blocking DNAs were added in either of the GISH probing steps. Images were acquired using a fluorescence microscope (Olympus BX61) with a CCD camera (Cool Snapper, Photometrics), and processed using Photoshop ver. 6.0 (Adobe).

\section{Results}

Sequential FISH and GISH analysis was conducted on 12 randomly selected samples (E1-E12) of the domesticated E. nutans. First, FISH was carried out using AAG and $A f a-$ family probes (Fig. 1a-c, g-i, m). GISH was carried out on the same cells using genomic DNA probes of $H$. chilense and $P$. stipifolia, respectively (Fig. $1 \mathrm{~d}-\mathrm{f}, \mathrm{j}-1, \mathrm{n}, \mathrm{o}$ ).

All plants carried 42 chromosomes. Sequential GISH clearly classified all chromosomes into three genomes: $\mathrm{H}$, St, or Y. As a result, we found that the $\mathrm{H}, \mathrm{St}$, and $\mathrm{Y}$ genomes include 3 (Nos. 1, 2, 3), 5 (Nos. 1, 2, 3, 4, 5) and 5 (Nos. 1, 2, $3,4,5)$ metacentric chromosomes, respectively (Fig. 2). Other chromosomes in these genomes were sub-metacentric.

Most of the chromosomes showed signals of AAG satellite and/or $A f a$-family sequences. Specific hybridization of these chromosome markers discriminated each chromo- some. Well marked chromosomes were arbitrarily designated as 1-7 by their arm ratio and the relative length (Fig. 2). Since some of the chromosomes were polymorphisms among different individuals, the polymorphisms showing the greatest similarity in the distribution of hybridization signal, arm ratio and length were allocated to the same number (Fig. 2). As the genome to which the chromosome belongs is known by GISH, the chromosomes can be designated as, for example, H1, H2, St2, and Y5. In this designation, the numerals do not correspond with those of the homoeologous groups as used in the nomenclature system of the chromosomes of wheat and barley.

The FISH/GISH analyses revealed large polymorphisms in the chromosome pattern (Fig. 2 and Table 1). We designated these polymorphisms as a, b, c, and etc (Table 1). The chromosomes shown with the same letter indicate identical patterns of FISH/GISH signals. As E. nutans has 42 chromosomes $(2 n=6 x=42)$, we observed a total of 504 chromosomes for the 12 plants. We found at least two polymorphisms in all of the 21 chromosomes, except for in $\mathrm{H} 1$ and Y6 (Table 1). The H, St, and Y genomes demonstrated 36,42 , and 33 polymorphic patterns of chromosomes, respectively. Most of the plants carried the pattern in the homozygous state, although some were in the heterozygous state $(5.1 \%$; 13 in 252 chromosome pairs; Table 1$)$.

In addition to the polymorphism of FISH patterns, translocation was observed in 7 of the 12 plants. These were nonRobertsonian translocations, and were possibly produced by homoeologous chromosome recombination. The translocations were grouped into four types. Type I involved two reciprocal translocations between chromosomes H6a and Y5a (Fig. 1g, j and Fig. 2). Plants E1, E6, and E7 included the pair of translocations in the homozygous state, whereas E12 carried it in the heterozygous state (Table 1 and Fig. $1 \mathrm{~m}, \mathrm{n}$, o). Type II involved reciprocal translocations between the $\mathrm{H}$ and Y genome chromosomes. However, the FISH patterns of the AAG satellite and the Afa family, and also the translocation break-point by GISH, clearly demonstrated that the type II translocation was different from the type I translocation (Fig. 1b, e and Fig. 2 H5f, Y1c). Only one plant, E3, carried the type II translocation (Table 1). Type III was a translocation between the $\mathrm{H}$ and $\mathrm{St}$ genome chromosomes (Fig. 2 H4b). However, no other counterpart was observed in the plants. One plant, E4, contained only one such translocation (Fig. 1c, f). Similar to Type III, Type IV was a translocation between the $\mathrm{H}$ and St genome chromosomes; however, it is mostly the St genome chromosome with a small chromosome segment of an $\mathrm{H}$ genome chromosome (Fig. 2 St3g). Plant E11 included one chromosome of type IV translocation (Fig. 1i, 1).

The karyotypes of the 12 plants were different from each other, and most chromosomes possessed polymorphisms at a high frequency. However, the heterozygosity was relatively low, suggesting that, in the domesticated strains of $E$. nutans used here, propagation was mainly by self-pollination or in a sib-crossing manner. 


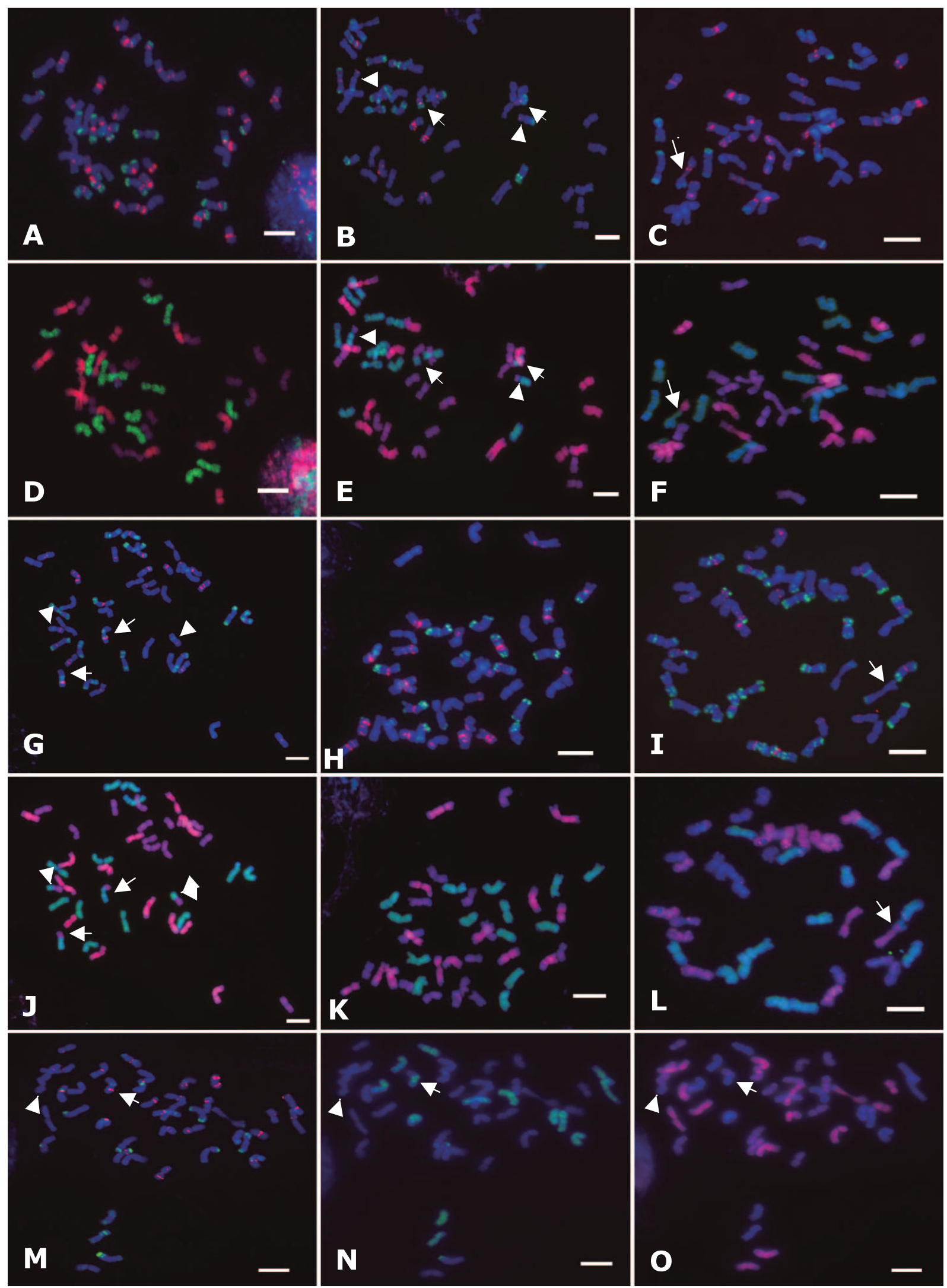

Fig. 1. Sequential FISH and GISH patterns of representatives of grass forage E. nutans. A, B, C, G, H, I, and M: FISH patterns of plants E2, E3, E4, E7, E8, E11, and E12 probed with AAG (red) and Afa family (green). D, E, F, J, K, and L: Sequential GISH patterns of E2, E3, E4, E7, E8, and E11 probed with genomic DNAs of H. chilense (H genome; green) and P. stipifolia (St genome; red). N, O: Sequential GISH patterns of E12 probed separately with $H$. chilense (green) and P. stipifolia (red). Arrows and arrowheads indicate translocation chromosomes. Scale bar $=10 \mu \mathrm{m}$. 


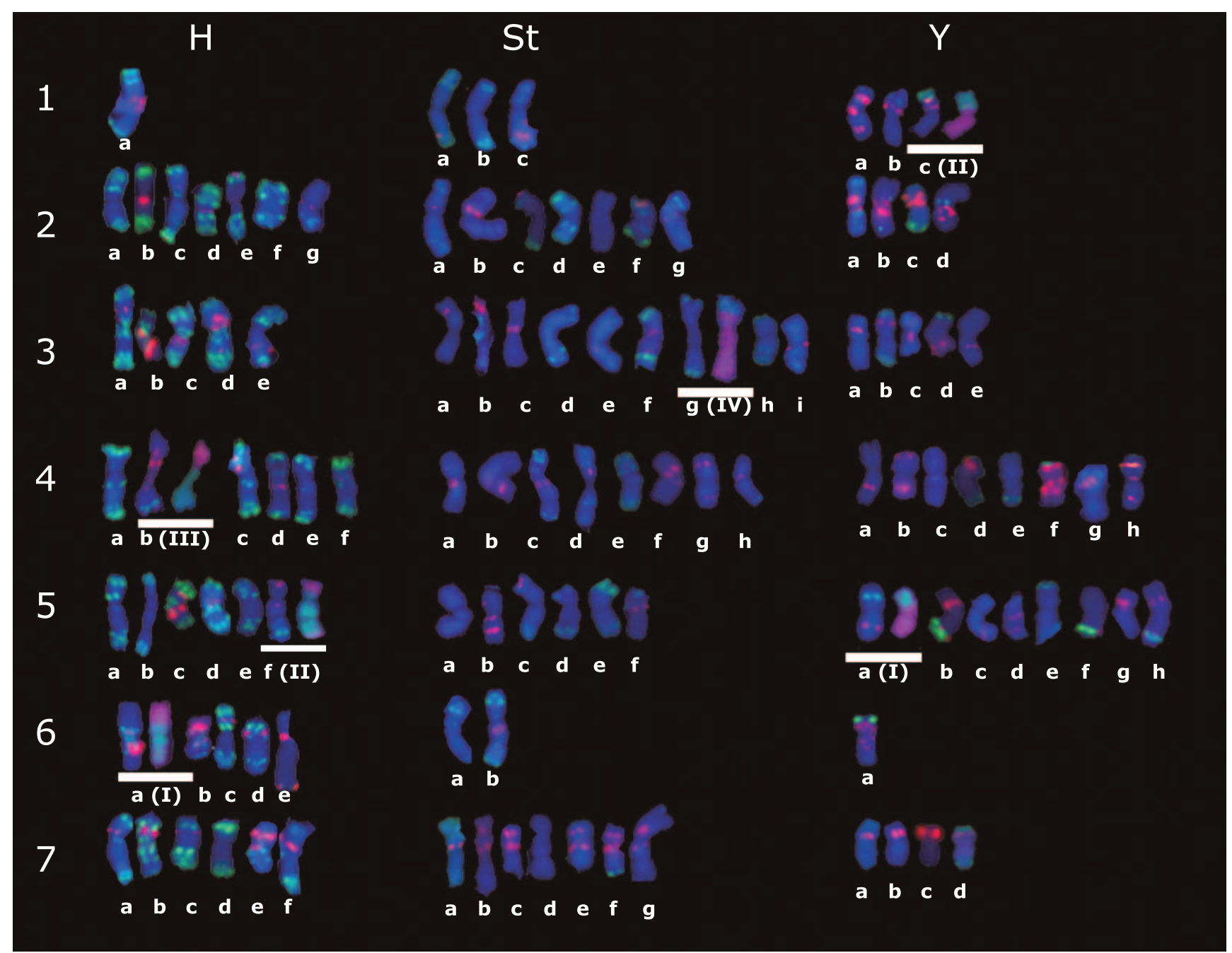

Fig. 2. Karyotypes of the 12 E. nutans plants. Different variants are annotated by the different roman letters. Translocations are indicated by I-IV.

\section{Discussion}

In this study, genomes $\mathrm{H}, \mathrm{St}$, and $\mathrm{Y}$ of $E$. nutans were successfully analyzed and each chromosome was assessed by sequential FISH and GISH. The Y genome is a basic genome occurring in the genus Elymus, but its progenitor is still unknown. Based on the molecular phylogenetic data, Liu et al. (2006) suggested that the Y genome probably shares a common progenitor with the St genome. We showed that the $\mathrm{Y}$ genome could be well distinguished from the St genome in E. nutans by GISH. This suggests that, despite sharing the same progenitor, there is genetic divergence between the St and Y genomes.

Using FISH with microsatellite and repetitive sequences, the karyotypes were shown to be largely polymorphic in most chromosomes. In addition, many were present in a homozygous state. This indicates that the plants of the domesticated strains of $E$. nutans propagated in a self-pollinated or a sib-crossing manner. The high seed setting in isolated spikes of $E$. nutans indicates a self-pollination habit (inbreeder), but it is also common to find spontaneous hybrids between
E. nutans and other Elymus taxa in nature (Lu 1993). E. nutans is originally a possible out-crossing species in the natural population, and this can be confirmed by the rate of polymorphisms of the karyotype. During the domestication process, there was marked selection pressure in a small population. Exceptions are seen in chromosomes $\mathrm{H} 1$ and Y6, which are conservative and monomorphic. This may suggest the presence of key genes on these two chromosomes.

Lu (1993) conducted meiosis analysis of the single intraspecific hybrid and its parental accessions, which belonged to two different populations of $E$. nutans. The results showed that there was a low frequency of univalency and multivalency in parental accessions, and an increased frequency of multivalency at metaphase I. In addition, there were chromatid bridges and fragments at anaphase I in the intraspecific hybrid. This, it was suggested that certain chromosome rearrangements occurred in different populations of the species.

Four types of translocation were observed in the plants. These were probably produced by recombination between homoeologous chromosomes belonging to different genomes 
Table 1. Chromosome variants included in karyotypes of 12 investigated samples (E1-E12)

\begin{tabular}{|c|c|c|c|c|c|c|c|c|c|c|c|c|c|c|c|}
\hline & & E1 & E2 & E3 & E4 & E5 & E6 & E7 & E8 & E9 & E10 & E11 & E12 & $\begin{array}{c}\text { No. of } \\
\text { variants }\end{array}$ & Total \\
\hline \multirow{7}{*}{$\mathrm{H}$} & 1 & $\mathrm{a}$ & $\mathrm{a}$ & $a$ & $a$ & $\mathrm{a}$ & $a$ & $\mathrm{a}$ & $\mathrm{a}$ & $\mathrm{a}$ & $\mathrm{a}$ & $a$ & $\mathrm{a}$ & 1 & \\
\hline & 2 & $\mathrm{a}$ & $\mathrm{b}$ & $\mathrm{de}$ & $\mathrm{a}$ & $\mathrm{d}$ & $\mathrm{a}$ & $\mathrm{a}$ & $\mathrm{f}$ & $\mathrm{c}$ & $\mathrm{fg}$ & $\mathrm{b}$ & $\mathrm{f}$ & 7 & \\
\hline & 3 & $\mathrm{a}$ & $\mathrm{b}$ & $\mathrm{e}$ & $\mathrm{a}$ & $\mathrm{d}$ & $\mathrm{a}$ & $\mathrm{a}$ & $\mathrm{d}$ & $\mathrm{c}$ & $\mathrm{d}$ & $\mathrm{c}$ & $\mathrm{d}$ & 5 & \\
\hline & 4 & $\mathrm{a}$ & $\mathrm{c}$ & $\mathrm{d}$ & $a b^{\mathrm{T}}$ & $\mathrm{e}$ & $\mathrm{a}$ & $\mathrm{a}$ & $\mathrm{e}$ & $\mathrm{cd}$ & $\mathrm{f}$ & $\mathrm{c}$ & $\mathrm{f}$ & 6 & 36 \\
\hline & 5 & $\mathrm{a}$ & $\mathrm{c}$ & $\mathrm{f}^{\mathrm{T}}$ & $\mathrm{b}$ & $\mathrm{e}$ & $\mathrm{a}$ & $\mathrm{a}$ & $\mathrm{e}$ & $\mathrm{d}$ & $\mathrm{e}$ & $\mathrm{d}$ & $\mathrm{e}$ & 6 & \\
\hline & 6 & $a^{T}$ & $\mathrm{c}$ & $\mathrm{b}$ & $\mathrm{b}$ & $\mathrm{d}$ & $a^{\mathrm{T}}$ & $a^{T}$ & $\mathrm{e}$ & $\mathrm{c}$ & bd & $\mathrm{c}$ & $\mathrm{a}^{\mathrm{T}} \mathrm{b}$ & 5 & \\
\hline & 7 & $\mathrm{a}$ & $\mathrm{a}$ & $\mathrm{c}$ & $\mathrm{a}$ & $\mathrm{c}$ & $\mathrm{a}$ & $\mathrm{a}$ & $\mathrm{d}$ & b & $\mathrm{c}$ & $\mathrm{b}$ & ef & 6 & \\
\hline \multirow{7}{*}{$\mathrm{St}$} & 1 & $\mathrm{a}$ & $\mathrm{c}$ & $\mathrm{b}$ & $\mathrm{b}$ & $\mathrm{b}$ & $\mathrm{b}$ & $\mathrm{b}$ & $\mathrm{b}$ & $\mathrm{c}$ & $\mathrm{b}$ & $\mathrm{b}$ & $\mathrm{b}$ & 3 & \\
\hline & 2 & $\mathrm{a}$ & $\mathrm{c}$ & $\mathrm{e}$ & $\mathrm{b}$ & $\mathrm{f}$ & b & $\mathrm{a}$ & ef & $\mathrm{d}$ & $\mathrm{fg}$ & $\mathrm{d}$ & $\mathrm{g}$ & 7 & \\
\hline & 3 & $\mathrm{a}$ & $\mathrm{e}$ & $\mathrm{h}$ & b & $\mathrm{h}$ & $\mathrm{c}$ & $\mathrm{d}$ & $\mathrm{h}$ & $\mathrm{e}$ & $\mathrm{i}$ & $\mathrm{fg}^{\mathrm{T}}$ & $\mathrm{i}$ & 9 & \\
\hline & 4 & $\mathrm{a}$ & $\mathrm{e}$ & $\mathrm{e}$ & b & $\mathrm{f}$ & $\mathrm{c}$ & $\mathrm{d}$ & gh & e & $\mathrm{e}$ & $\mathrm{e}$ & $\mathrm{g}$ & 8 & 42 \\
\hline & 5 & $\mathrm{a}$ & $\mathrm{c}$ & e & $\mathrm{a}$ & $\mathrm{f}$ & $\mathrm{a}$ & b & $\mathrm{e}$ & $\mathrm{c}$ & $\mathrm{e}$ & d & e & 6 & \\
\hline & 6 & $\mathrm{a}$ & $\mathrm{b}$ & b & $\mathrm{a}$ & b & b & $\mathrm{a}$ & $\mathrm{a}$ & b & $\mathrm{b}$ & $\mathrm{a}$ & b & 2 & \\
\hline & 7 & $\mathrm{a}$ & $\mathrm{c}$ & $\mathrm{d}$ & b & $\mathrm{e}$ & b & $\mathrm{a}$ & $\mathrm{fg}$ & $\mathrm{c}$ & $\mathrm{e}$ & $\mathrm{c}$ & $\mathrm{e}$ & 7 & \\
\hline \multirow{7}{*}{$\mathrm{Y}$} & 1 & $\mathrm{a}$ & $\mathrm{a}$ & $\mathrm{c}^{\mathrm{T}}$ & $\mathrm{a}$ & $\mathrm{a}$ & $\mathrm{a}$ & $\mathrm{a}$ & $\mathrm{a}$ & $\mathrm{a}$ & $\mathrm{a}$ & $\mathrm{a}$ & $b$ & 3 & \\
\hline & 2 & $\mathrm{a}$ & $\mathrm{a}$ & $\mathrm{c}$ & b & c & $\mathrm{a}$ & $\mathrm{a}$ & $\mathrm{a}$ & $\mathrm{a}$ & $\mathrm{c}$ & $\mathrm{a}$ & $\mathrm{d}$ & 4 & \\
\hline & 3 & $\mathrm{a}$ & $\mathrm{b}$ & $\mathrm{e}$ & $\mathrm{a}$ & $\mathrm{d}$ & $\mathrm{a}$ & $\mathrm{a}$ & $\mathrm{a}$ & $\mathrm{c}$ & $\mathrm{a}$ & $b$ & $\mathrm{e}$ & 5 & \\
\hline & 4 & $\mathrm{a}$ & $\mathrm{d}$ & $\mathrm{e}$ & b & $\mathrm{f}$ & $\mathrm{c}$ & $\mathrm{c}$ & $\mathrm{c}$ & $\mathrm{c}$ & $\mathrm{g}$ & $\mathrm{c}$ & $\mathrm{h}$ & 8 & 33 \\
\hline & 5 & $\underline{\mathrm{a}}^{\mathrm{T}}$ & $\mathrm{c}$ & $\mathrm{f}$ & b & $\mathrm{g}$ & $\underline{\mathrm{a}}^{\mathrm{T}}$ & $\underline{\mathrm{a}}^{\mathrm{T}}$ & $\mathrm{h}$ & $\mathrm{d}$ & b & $\mathrm{e}$ & $\mathrm{ga}^{\mathrm{T}}$ & 8 & \\
\hline & 6 & $\mathrm{a}$ & $\mathrm{a}$ & $\mathrm{a}$ & $\mathrm{a}$ & $\mathrm{a}$ & $\mathrm{a}$ & $\mathrm{a}$ & $\mathrm{a}$ & $\mathrm{a}$ & $\mathrm{a}$ & $\mathrm{a}$ & $\mathrm{a}$ & 1 & \\
\hline & 7 & $\mathrm{a}$ & $\mathrm{c}$ & $\mathrm{d}$ & b & $b$ & b & $b$ & $\mathrm{~b}$ & $b$ & $\mathrm{~b}$ & $\mathrm{~b}$ & b & 4 & \\
\hline
\end{tabular}

* letters with superscript as "T" indicate translocations; columns containing two letters indicate the heterozyogote for the chromosomes.

because many plants carried the translocations in the homozygous state. If the translocation had occurred between nonhomoeologous regions of certain chromosomes, pollen with non-compensating translocations that appeared after meiosis would have a lesser chance for fertilization during pollen competition and thus would not be homozygous. The translocations, possibly by homoeologous recombination, might be induced in the process of hybridization between different species, due to the misbalance in the pairing system of homoeologous chromosomes $(p h)$ after hybridization. Although homoeologous translocations occurred at a high frequency via this process, only limited translocations that developed a new, balanced $p h$ system and adapted well to the environment were selected by nature. It is confirmed that most plants retained their basic chromosome structure without translocations.

High genetic diversity is beneficial for E. nutans to deal with environmental hardness. However, karyotypes with homoeologous recombination cause aberration in meiosis and this affects seed setting. Seed products are a very important characteristic of forage production. Thus, the seed yield of the domesticated forage plant $E$. nutans can be improved by genetic homogeneity selection.

The plant materials of $E$. nutans used in this study were collected and domesticated from the natural population by breeders. Information relating to their original population is now lacking. Detailed studies of the genetic composition and variation in natural populations of this species may provide valuable information for the evolution, adaptation, and utilization of this species for a forage crop.

\section{Acknowledgments}

This work was partially supported by the "Light of the West" talent cultivation plan of the Chinese Academy of Sciences.

\section{Literature Cited}

Cuadrado, A. and T. Schwarzacher (1998) The chromosome organization of simple sequence repeats in wheat and rye genomes. Chromosoma 107: 587-594.

Kishii,M., K.Nagaki, H.Tsujimoto and T.Sasakuma (1999) Exclusive localization of tandem repetitive sequence in subtelomeric heterochromatin regions of Leymus racemosus (Poaceae, Triticeae). Chromosoma 7: 519-529.

Liu, Q.L., S.Ge, H.B.Tang, X.L.Zhang, G.F.Zhu and B.R.Lu (2006) Phylogenetic relationships in Elymus (Poaceae: Triticeae) based on the nuclear ribosomal internal transcribed spacer and chloroplast trnL-F sequences. New Phytol. 170: 411-420.

Löve,A. (1984) Conspectus of the Triticeae. Feddes Repertorium 95: 425-521.

Lu,B.R. (1993) Meiotic studies of Elymus nutans and E. jacquemontii (Poaceae, Triticeae) and their hybrids with Pseudoroegneria spicata and seventeen Elymus species. Plant Syst. Evol. 186: 193212.

Nagaki,K., H.Tsujimoto, K.Isono and T.Sasakuma (1995) Molecular characterization of a tandem repeat, Afa-family, and distribution among Triticeae. Genome 38: 479-486.

Pedersen,C., S.K.Rasmussen and I.Linde-Laursen (1996) Genome and chromosome identification in cultivated barley and related species of the Triticeae (Poaceae) by in situ hybridization with the GAAsatellite sequence. Genome 39: 93-104. 
Tsujimoto,H., Y. Mukai， K. Akagawa， K. Nagaki， J.Fujigaki， M Yamamoto and T.Sasakuma (1997) Identification of individual barley chromosomes based on repetitive sequences: conservative distribution of Afa-family repetitive sequences on the chromosomes of barley and wheat. Genes. Genet. Syst. 72: 303-309.

Ørgaard,M. and J.S.Heslop-Harrison (1994) Investigation of genome relationships between Leymus Psathyrostachys and Hordeum inferred from genomic DNA: DNA in situ hybridization. Ann. Bot. London 73: 195-203.
Wang, R.R-C., R.v.Bothmer, J.Dvorak, G.Fedak, I.Linde-Laursen and M.Muramatsu (1995) Genome symbols in the Triticeae. In: Wang, R.R.-C., K.B.Jensen and C.Jaussi (eds.) Proc. 2nd Int. Triticeae Symp., June 20-24, 1994, Logan, Utah, Utah State University Publication Design.

Zhang,J.B., S.Q.Bai, X.Q.Zhang, X.Mao and J.J.Yan (2008) Karyotypes of 12 Elymus nutans $\mathrm{L}$. in the northwest plateau of Sichuan province. Acta Bot. Boreal. Occident. Sin. 28: 946-955. 